\title{
Preceptor Barriers and Motivators
}

\author{
Anna Jarrett, Marilou Shreve, Audrey Weymiller \\ University of Arkansas Eleanor Mann School of Nursing \\ Fayetteville, AR United State of America
}

\begin{abstract}
Preceptors for doctor of nursing practice students (DNP) are essential for student and program success. In order to learn the clinical role, DNP students must have qualified preceptors. In the United States, students must compete with students from multiple programs to secure their preceptor(s). It is important to understand why preceptors agree to do this without pay. In order to more efficiently assist student recruit preceptors, the Enlisting New Teachers in Clinical Environments (ENTICE) survey was used to discover barrier and motivators for being a preceptor. A beginning and advanced clinic course were selected for baseline data in 2015, and compared with 2016 preceptor responses. Next, surveys were compared by student cohorts longitudinally across courses. In these groups of preceptors across courses and across cohorts, 'giving back to the profession' remained the most important reason these preceptors chose to teach students in the clinical arena while practicing their skills. The most significant barrier for preceptors in both years for both courses and for preceptors in Cohort 1 and 2 across courses was 'decreased productivity'. The 'type of student' was also important. The solution to this problem may be standardized preceptor guidance programs, interprofessional education, online learning opportunities, standardized student pre-clinical competency validation, and negotiating professional entrustable acts.
\end{abstract}

\section{Introduction}

As the shortage of medical providers increase, the number of nurse practitioner students entering doctoral level programs also increase.
Preceptors for doctorate of nursing practice (DNP) students play a vital role in the education of the next generation of providers [1]. Many providers decide to be preceptors for DNP students to give back to their profession. Preceptors are committed to their role in educating future practitioners and want the preceptor process to be legitimized and recognized by employers and facilities [2]. Preceptors find support from nurse educators to assist in increasing their awareness and confidence of the preceptor role.

\section{Literature Review}

A preceptor is one who teaches, supports, counsels, coaches, evaluates, serves as a role model, and socializes DNP students to their new role as a provider. The role is essential to help the student assimilate academic knowing into the real work of practice. Students have the luxury of being a learner by a 1:1 relationship with a practicing provider. It allows time for the student to gain confidence while perfecting their advanced skills.

Being a good preceptor requires someone who is competent in practice and someone who can intuitively shift between coaching, mentoring, teaching, and role modeling. Students' objectives for advanced practice nursing in clinical set $\mathrm{ting} \mathrm{s}$, the focus is on attainment of pre- determined skill sets appropriate for one's area of specialty. For example, family nurse practitioners learn skills with patients across the lifespan, but adult geriatric nurse practitioners do not learn specialty skills for pediatric populations.

In 2015, The University of Arkansas Eleanor Mann School of Nursing was awarded an Advanced Nursing Education gran t supported by the Health Resources and Services Administration (HRSA) of the U.S. Department of Health and Human Services (HHS) to improve the preceptor/student/faculty process. 
This project called, "Mutually Beneficial Clinical Partnerships" had three major goals with methods to measure outcomes. One goal was to evaluate the clinical preceptor process. The instrument was selected after a careful review of the literature in search of reliable and valid instruments to measure student, preceptor and faculty satisfaction. It was discovered that students evaluate preceptors, faculty evaluate preceptors, and preceptors evaluate students, but the only instrument that 'got at' the reason preceptors agree to become preceptors was the Enlisting New Teachers in Clinical Environments (ENTICE): novel ways to engage clinicians[3].

ENTICE was a survey created and piloted by researchers at Duke University in collaboration with the Veterans' Affairs Medical Center located in Durham, North Carolina in 2013 and was piloted and published in 2014. This group studied incentives and barriers to being a preceptor for medical students assigned to primary care [3]. However, studies have not examined barriers and motivation for preceptors working with graduate nursing students. From an exhaustive review of literature and under the guidance of collaborators with expertise developing surveys, the collaborative team constructed a survey comprised of six demographic questions. Seven questions aimed to determine past experience as a preceptor and seven "looking forward" questions were developed to discover future willingness to precept students.

One key question in this area asked preceptors to rank from 1 MOST significant to 5 LEAST significant barriers to being a preceptor. From the literature review the following options were given:
a) Decreased productivity as a result of time required to teach students
b) Inability of learner to write clinic notes in the electronic medical record due to Institutional protected health information policies
c) Lack of institution, department, professional recognition for teaching
d) Lack of physical space
e) Lack of support among office clinical colleagues
f) Lack of teaching skills
g) Patients prefer to see provider without students
h) Time to teach results in longer work days
i) Type of learner (i.e., MD/NP/PA) determines willingness to precept
j) Other

Both survey questions gave an option for 'other' in order to allow participants to give additional input or different reasons. The second question was posed similarly with 1 MOST significant to 5 LEAST significant incentives to being a preceptor. The following options were given:

$\begin{array}{ll}\text { a) } & \text { Access to online training modules } \\ \text { b) } & \begin{array}{l}\text { Adjusted appointment times to } \\ \text { incorporate feedback to learner }\end{array} \\ \text { c) } & \begin{array}{l}\text { Certificate or plaque of appreciation } \\ \text { from facility or academic institution }\end{array} \\ \text { d) } & \text { Enhanced employee benefit package } \\ \text { e) } & \begin{array}{l}\text { Faculty appointment with affiliated } \\ \text { academic department }\end{array} \\ \text { f) } & \text { Monetary compensation } \\ \text { g) } & \text { Parking passes } \\ \text { h) } & \begin{array}{l}\text { Protected time to attend preceptor } \\ \text { education }\end{array} \\ \text { i) } & \text { Reduced productivity expectations (i.e., } \\ \text { reduced encounters, RVUs) } & \text { It allows one to give back to profession } \\ \text { j) } & \text { Other } \\ \text { k) } & \end{array}$

In 2013, 180 providers were sent the 20-question survey. The response rate was $50 \%$, with $65 \%$ of those participants indicating they planned to be a preceptor within the next six months. The overall findings of this study found time pressure and productivity demands were the most important barriers to being a preceptor [1].

Interprofessional education aims to utilize members of different professions to learn together, with each other and about each other [4]. Standardized assessments are national certification examinations taken by students after 500 hours of clinical practice experiences in the DNP program.

DNP students do not receive certification until they graduate from the DNP program, but they have the comfort of knowing they meet national minimum requirements for advanced practice nursing.

Competency assessments for students are administered throughout the program after a skills laboratory experience. In addition, faculty, and students participate in DNP orientation. Faculty members provide evaluation oversight and indirect supervision for DNP students.

In 2016, the National Organization for Nurse Practitioner Faculty (NONPF) and the American Association of Colleges of Nursing (AACN) created a joint National Task Force on Quality Nurse Practitioner Education who examined core competencies for preceptors. 
These two powerful organizations within this joint task force for advanced practice nursing added Criterion IV.B.3.c., which states that preceptors are oriented to program/track requirements and expectations for oversight and evaluation of Nurse Practitioner Students. Nursing programs in the United States who are accredited institutions must put a mechanism in place to that requires preceptors to have an orientation to the program where they precept prior to being approved as a preceptor [6].
Specific preceptor competencies were developed using the 2016 Interprofessional Education Collaborative Core Competencies [4]. The competencies were developed around the four general competencies and sub-competencies sequestered around values/ethics for interprofessional practice and communication, roles and responsibilities, and teams/teamwork. This is available and distributed to new preceptors at the time they agree to work as a preceptor (see Table 1).

Table 1.DNPpreceptorcompetencies

\section{DNP PRECEPTOR COMPETENCIES}

1. Maintains skills, certification licensure and uses current practice guidelines as an indicator of competence.

2. Conveys one's limitations in skills, knowledge, and abilities to student and clinical co-preceptor.

3. Ensures that student respects the dignity and privacy of patients while maintaining confidentiality.

4. Uses knowledge, skills, and abilities of available health professionals and healthcare workers to provide care that is safe, timely, efficient, effective, and equitable.

5. Maintains a climate of mutual respect and shared values with student and other professions.

6. Prioritizes interests of patients and populations central to interprofessional health care delivery.

7. Role models leadership embracing cultural diversity and individual differences to establish a high standard of ethical conduct toward student, patients, families, and other collaborative team members.

8. Communicates with student, patients, families, communities, and other health professionals in a responsive and responsible manner that supports a team approach to maintenance of health and treatment

9. Explains roles and responsibilities of care providers and how the team works together to execute a treatment

10. Engages self and student to constructively manage disagreements about values, roles, goals, and actions that arise among healthcare professionals and with patients and families.

11. Encourages student to express knowledge to team members involved in patient care with confidence, clarity, and respect, and work to ensure understanding of information, treatment \& care decisions.

12. Engages in continuous development and process improvement strategies to increase effectiveness of interprofessional teamwork and to enhance team performance appropriate to

13. Provides timely, sensitive, instructive feedback to student and clinical co-preceptor (faculty) about student's performance.

14. Other site specific or skill specific competency 
In addition, new preceptors are expected to complete an online preceptor orientation course which introduces them to academic expectations, course outcomes, and the evaluation process. As of fall 2017, in order to be approved as a preceptor, they must take the online course and pass with at least $80 \%$. To date, only one preceptor had to repeat the course. It is construction in three short modules. The first model introduces the Clinical Co-Preceptor
Model which aims to improve preceptor, student, and faculty communication. This model incorporates entrustable professional acts, standardized student assessment, interprofessional education, and innovative education practices as outcomes for graduate doctor of nursing practice (DNP) students [5]. See figure 1.

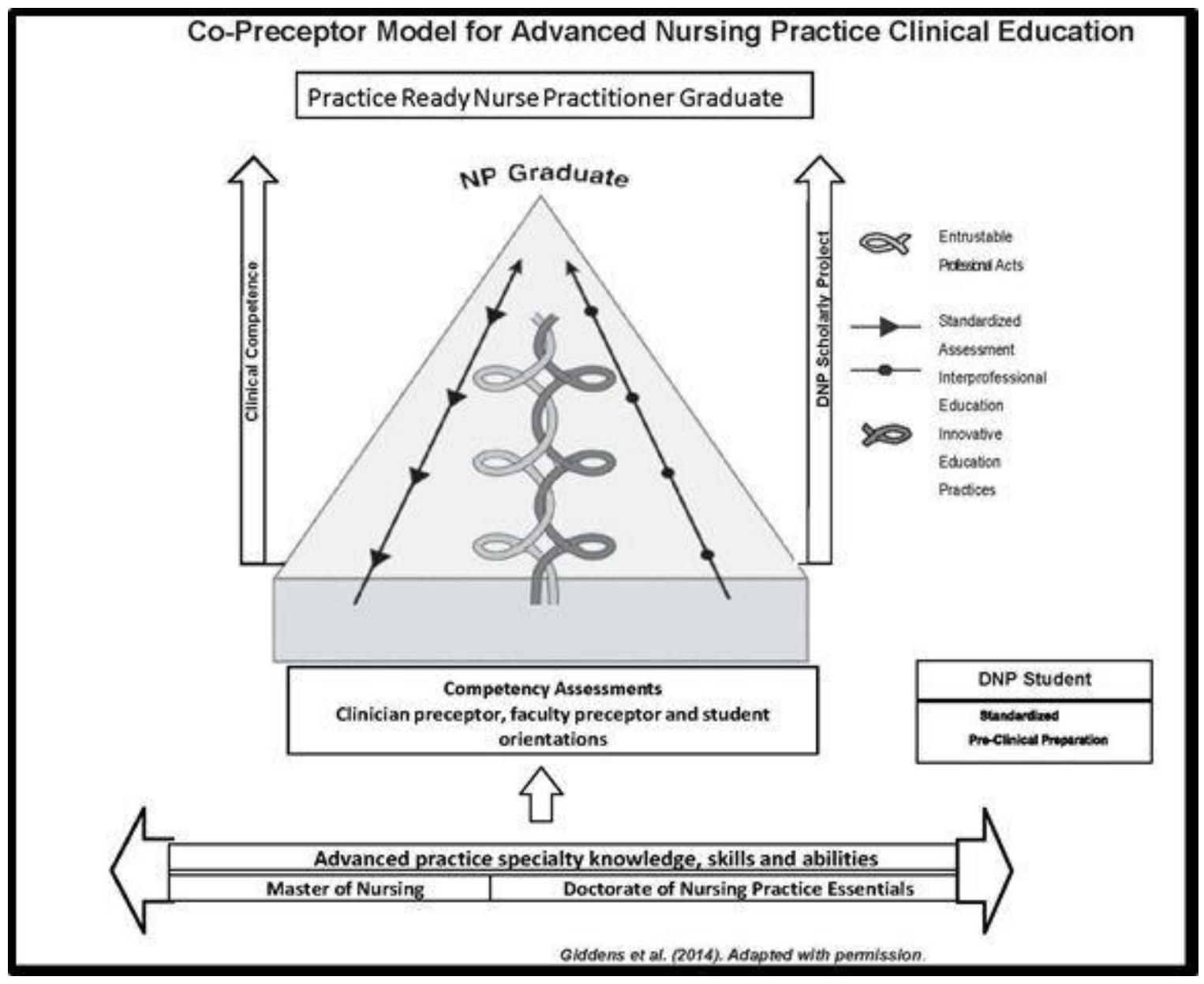

Figure1.Co-Preceptormodel

As part of program evaluation, the ENTICE survey was selected to be administered to current preceptors for graduate nursing students across cohorts over a 3 -year period of time $(2015-2018)$. Results are collected, analyzed and disseminated to graduate nursing faculty at the end of each semester.
Because this instrument was originally designed for medical students, phrases indicating medical students were substituted with nurse practitioner and clinical nurse specialist students. The original study did not attempt to establish initial reliability and validity. 
In addition, because this pilot study has a small $\boldsymbol{n}$ for each cohort, establishing reliability using measures of internal consistency or repeated measures was not calculated. The original class sizes were small with a mean class size of eight students across cohorts, but as the program grows it may be possible to establish internal consistency of this instrument.

Usability was determined by four individual preceptors' feedback in a face-to-face meeting at two institutions. All four preceptors indicated the survey was easy to understand and straightforward. They had no additions to either barriers or motivators.

Face and content validity was established by four faculty members who have had at least five years' experience in academic teaching, preceptorship, and clinical practice. There was $100 \%$ consensus that items listed regarding barriers were correct and complete. There was $75 \%$ consensus among these experts about motivators for preceptors. One expert felt faculty appointment with affiliated academic department should be omitted because it was not possible to offer this incentive by the academic institution per policy.

At the end of the first year, responses of preceptors for an advanced and beginner clinical course were described and compared. The ENTICE survey and study was used with permission and approved through University IRB and completed by preceptors for a family nurse practitioner program at the end of each clinical course. The first and last clinical skills courses are compared.

\section{Baseline Advanced course (AC) 2015}

There were 4 of 7 (57\%) preceptors responding to the initial ENTICE survey. Three preceptors were APRNs; $50 \%$ were in a specialty practice, $25 \%$ in hospitalist roles. The age span was 28 - 49 years of age; $75 \%$ were Caucasian; one preceptor was African American. There was a wide disparity in number of years as a preceptor; $50 \%$ stated less than one year; $50 \%$ reported $14-17$ years. Surprisingly, $75 \%$ reported they felt the ideal number of months to be a preceptor was 5-6 months/year, but only 50\% felt they would be a preceptor in the next six months.

In addition to basic and specific demographics, the survey consisted of two domains: 1) potential barriers to decide not to be a preceptor and 2) reasons one would begin or continue to be a preceptor. Preceptors were asked about potential barriers in their decision to consider to precept NP/CNS students and to rank the top 5 reasons why they would not precept the students. Responses were ranked as $1=$ most significant barrier, $2=$ second most significant barrier, 3 = third most significant barrier, $4=$ fourth most significant barrier and $5=$ least significant barrier.

Decreased productivity of the preceptor (decreased visit volume and RVUs) and the type of student (level of nursing practice, i.e., baccalaureate, masters or doctoral nursing student) tied with a mean score of 2.5. For these preceptors, this was a significant barrier and would determine if they would continue to be a preceptor. The least potential barriers included the inability of student to write a clinical note in the electronic health/medical records $(\boldsymbol{M}=4.25)$, lack of department/professional recognition for teaching/being a preceptor $(\boldsymbol{M}=$ 4.25), lack of physical space (i.e., not enough exam rooms) $(\boldsymbol{M}=5)$, and patients prefer to see the provider without students $(\boldsymbol{M}=4.5)$.

Reasons why preceptors were considering starting or continuing as a preceptor were posed. The same rating scale 1-5 above was used with $1=$ most significant incentive and $5=$ least significant incentive. The choices listed for reasons to consider include: access to online training modules with CME/Contract hours for provider, adjusted appointment times to incorporate time for feedback to student, certificate or plaque of appreciation from institution/department, enhances employee benefit package, faculty appointment with affiliated academic department, monetary compensation, parking passes for school of nursing access for related obligations, protected time to attend preceptor specific workshops or educational sessions, reduced productivity expectations (i.e., reduction in encounters, visit volume, or RVUs), teaching/being a preceptor gives the preceptor the opportunity to give something back to the profession.

The most significant reason by the preceptors to consider beginning or continuing to precept is access to online training modules with continuing education/contact hours for providers $(\boldsymbol{M}=2.5)$.

Adjustment in appointment times to incorporate time for feedback to students, monetary compensation, and teaching and being a preceptor give the preceptor the opportunity to give something back to the profession 
scored second highest $(\boldsymbol{M}=2.75)$. The least significant reason $(\mathrm{M}=5.0)$ was parking passes for campus related obligations.

\section{Baseline Beginner class (BC) 2015}

There were 6 of $6 \quad(100 \%)$ preceptors responding to the initial ENTICE survey. Five preceptors were APRNs; $50 \%$ were in family practice, with $33 \%$ in hospitalist roles. The age span was 44-55 years of age; all six were Caucasian. There was a wide spread in number of years as a preceptor; $50 \%$ states less than one year; $25 \%$ reported 6-9 years, and $25 \%$ had been a preceptor for $14-17$ years. $50 \%$ reported they felt the ideal number of months to be a preceptor was 5-6 months/year, and $50 \%$ felt they would be a preceptor in the next six months.

Decreasing the productivity of the preceptor (decreased visit volume and RVUs) scored low ( $M$ $=2.33$ ) on a reverse scaled question, which made it the most significant barrier for these preceptors. Two other selected barriers to being a preceptor for this course were lack of recognition (department and professional) and lack of teaching/preceptor skills $(\boldsymbol{M}$

= 3.81). The least potential barriers included lack of physical space (i.e., not enough exam rooms), length of clinical rotation/ hours, and lack of support among office clinical colleagues. $(\boldsymbol{M}=$ 4.67). The type of student and teaching/being a preceptor requires an inordinate amount of time which results in longer work days were not particularly significant for this group of preceptors $(\boldsymbol{M}=4.17)$.

The most significant reason selected by the preceptors to consider beginning or continuing to preceptor based teaching/being a preceptor gives the preceptor the opportunity to give something back to the profession $(M=1.83)$, followed by faculty appointment with affiliated academic department and access to online training modules with continuing education/contact hours for providers $(\boldsymbol{M}=2.83)$. A desire for adjusted appointment times $(M=3.33)$, and monetary compensation, certificate or plaque of appreciation from institution/department did not seem particularly important to this group of preceptors $(\boldsymbol{M}=4.0)$. Teaching and being a preceptor gave the preceptor the opportunity to give something back to the profession was a high priority $(\boldsymbol{M}=2.75)$ for this group. The least significant reason was having parking passes at school for related obligations $(\boldsymbol{M}=4.17)$.

\section{Findings}

There was general consensus among the preceptors from both clinical courses. Overall, the biggest barrier to being a preceptor was decreasing the preceptor's productivity, which may have a financial impact on the preceptor in the form of reimbursement, bonuses, and/or annual raises $(\mathrm{M}=2.5,2.33)$. The two most stated reasons for continuing to precept from the groups of current preceptors were to give back to profession ( $\mathrm{M}=2.75,1.83)$ and access to online continuing education with continuing education or contact hours $(M=2.50,2.83)$.

\section{2015 and 2016 (AC) Preceptor Responses}

Results were analyzed by cohorts once two groups had completed and evaluated the same course for two data points. The same courses were analyzed. First, the advance clinical course NURS 6244 was compared to the previous year's findings. Preceptors were not the same individuals, nor were students. For the second cohort in 2016 in the same advanced course, type of student was the most significant barrier preceptors identified $(\boldsymbol{M}=$ 2.00). However, decreased productivity was most significant for the first cohort in this course $(\boldsymbol{M}=$ 2.50). The least significant continues to be lack of physical space, which speaks well for the clinical environment in which preceptors and students practice $(\boldsymbol{M}=5.00)$. See figure 2 .

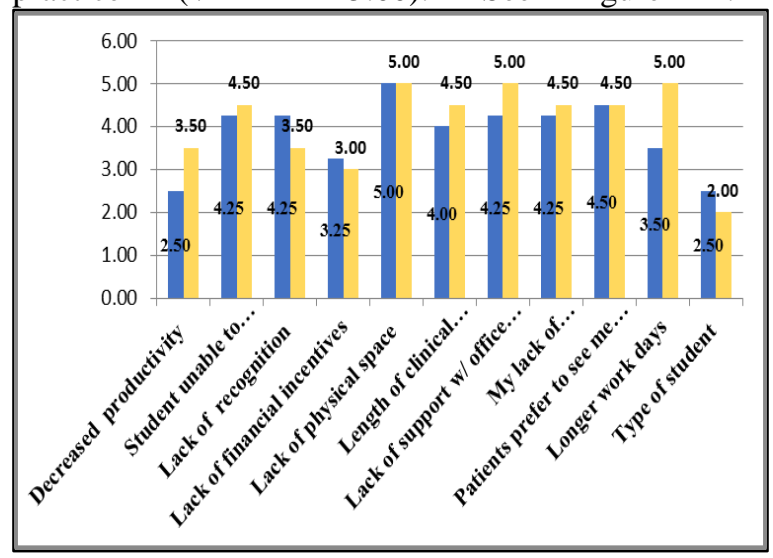

Figure 2. 2015 vs. 2016 AC barriers

Mean scores for all items increased from the advance course 3.84 to 4.09 from the first and second cohorts, which may imply overall less significance to 
most variables. This may also represent continued experience of the preceptors to teach the same course each year. Unexpectedly, the most significant motivator for preceptors in the second cohort was access to training $(\mathrm{M}=2.50)$, but for the first cohort it was to give back to the profession $(\boldsymbol{M}=1.50)$. The least significant motivator was parking passes for both cohorts $(\boldsymbol{M}=5.0)$, but reduced productivity and adjusted appointment times were less significant to the second cohort, perhaps because they are more experienced students, or the type of clinic and preceptor could possibly account for this change (see Figure 3).

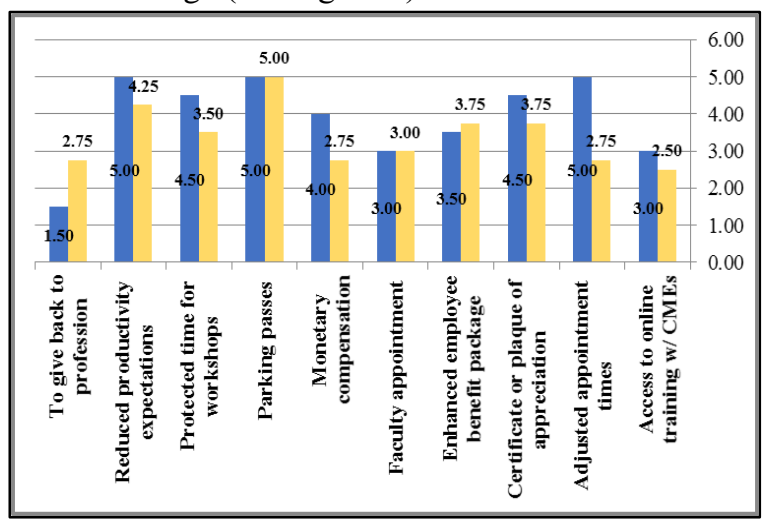

Figure 3.2015 vs. 2016 AC motivators

\section{2015 and 2016 (BC) Preceptor Responses}

Cumulative means across all data points for 20152016 beginner practitioner course show the decreased productivity on the part of the preceptors was the most significant barrier $(\boldsymbol{M}=2.33,1.60)$. Longer work days was the next most significant barrier for the second cohort $(\mathrm{M}=3.00)$. The remaining variables for both cohorts fell within a range $3.80-4.40$, which were closer to the high end of the scale, indicating they were not as significant to either group (see Figure 4).

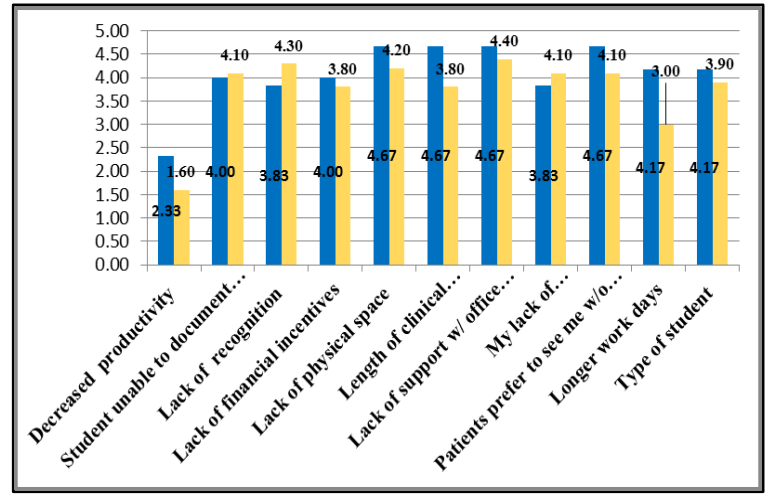

Figure 4. 2015 vs. 2016 BC barriers beginning clinical course were to give back to the profession $(M=2.70,1.83)$ and adjusted appointment times $(\boldsymbol{M}=3.50,3.33)$. Again, parking passes were not particularly significant (M $=5.00,4.17)$. A new motivator, Faculty appointments as adjunct faculty became more $\mathrm{i}$ $\mathrm{mportant}$ with the se cond cohort during the second year $(\mathrm{M}=4.50,2.83)$. Parking passes $(\mathrm{M}=5.00,4 / 17)$ and recognition $\mathrm{w} \mathrm{i}$ th certificate or plaque $(M=5.00,4.00)$ wa s les s significant to both groups (see Figure 5).

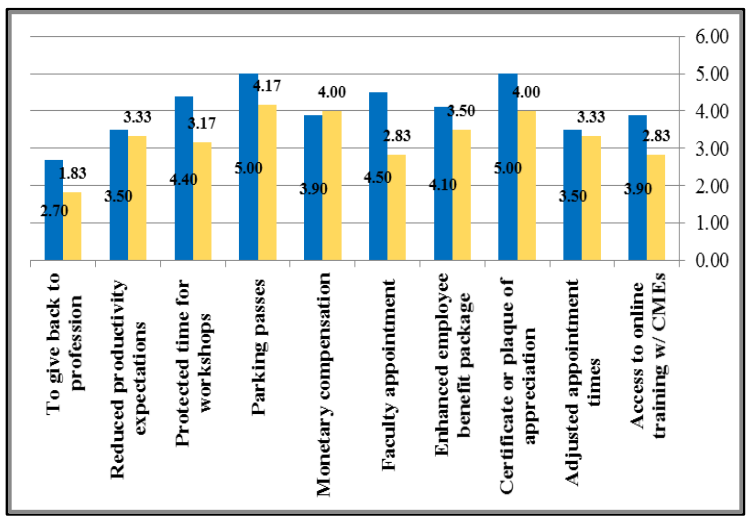

Figure 5. 2015 vs. 2016 BC motivators

\section{Preceptor Barriers (PB) Across Cohorts}

After enough longitudinal data had been collected from end-of-course surveys electronically submitted to preceptors over the period of time from fall 2015 until the beginning of fall 2017, surveys were extracted from the data source and compared across cohorts.

Cohort 1 consisted of students who entered the beginning clinical course spring 2016 and who had completed five clinical courses. A goal of the Advanced Nursing Education grant was to encourage students to select clinical placements in rural and underserved clinics and facilities and to participate in an emersion experience, which entailed staying in the same site and for most semesters to remain with the same preceptor. It is not possible to match preceptors with courses to determine if this was the same preceptors, due to IRB restriction of complete anonymity of the participants.

There were a total of 38 preceptors responding for cohort 1 across all courses completed to date, with a range of group mean scores between 2.95 and 4.36. Preceptors were 
asked to complete the survey with score of 1 being the most significant, and progressing to 5 being the $=$ least significant barrier. Consistent with comparisons between beginner and advanced courses, decreased productivity was the most significant barrier to being a preceptor for this cohort, regardless of where the student was in the progression of courses. Response rates appeared to increase over time. The range of responses were $26.3 \%$ to $69.2 \%$. This can be attributed to preceptors becoming aware of end-ofcourse expectations regarding survey completions. In addition to this voluntary survey, preceptors must complete two additional required surveys. Consistent with previous findings, altruism is evident in the least significant barrier to being a preceptor across courses was 'lack of recognition' (see Figure 6).

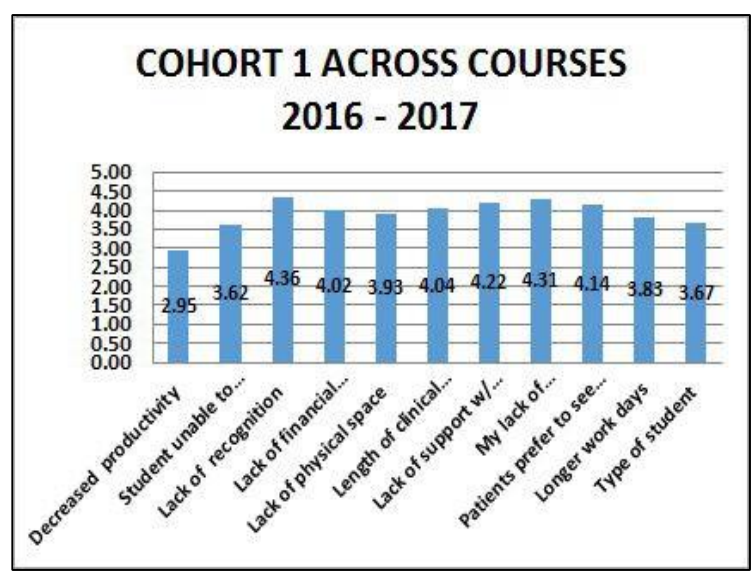

Figure 6. PB Cohort 1 across courses

Cohort 2 consisted of preceptor responses as longitudinal data collected over the period of time from fall 2016 until the beginning of fall 2017. Endof-semester surveys were extracted from the data source and compared across courses for this cohort as well. Cohort 2 consisted of students who entered the first clinical course fall 2016 and who had completed four clinical courses. These students and preceptors were well versed in the goals of the Advanced Nursing Education grant and had embraced emersion experiences.
There were a total of 25 preceptors responding for cohort 2 across courses with a range of group mean scores between 2.96 and 4.44, which compares closely with Cohort 1 preceptors. Decreased productivity was the most significant barrier to being a preceptor for this cohort, and once again, lack of recognition was the least significant barrier according to this group of preceptors.

This may indicate that the same preceptors were used for some students in both cohorts. Students discuss quality preceptors and make recommendations to newer cohorts to direct them in a quality experience. Altruistic reasons for being a preceptor continues to ring true, with the least significant barrier to being a preceptor across courses were 'lack of recognition' (see Figure 7).

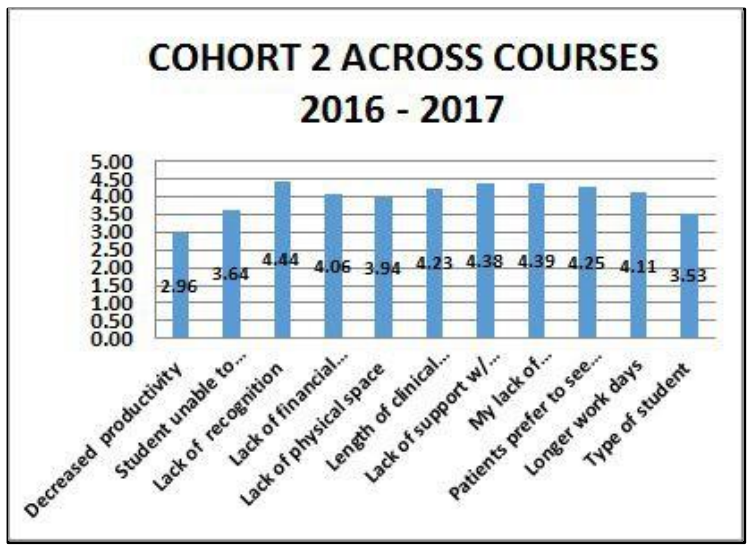

Figure 7. PM Cohort 2 across courses

\section{Preceptor Motivators (PM) Across Cohorts}

Response rates also increased over time. The range of responses were $26.1 \%$ to $70.1 \%$. This increase for second cohort is likely to be attributable to increased awareness of the role of preceptors.

Using the same procedure for barriers, preceptor motivators were examined across both cohort 1 and 2. The scale used reflected 1 as being the most significant, moving to 5 as the least significant motivator for being a preceptor. Cohort 1 preceptors were consistent with previous data with the most significant motivator being, 'to give back to the profession'. The range of scores were 2.53 to 4.58 , with an overall mean score 3.84 (see Figure 8). 


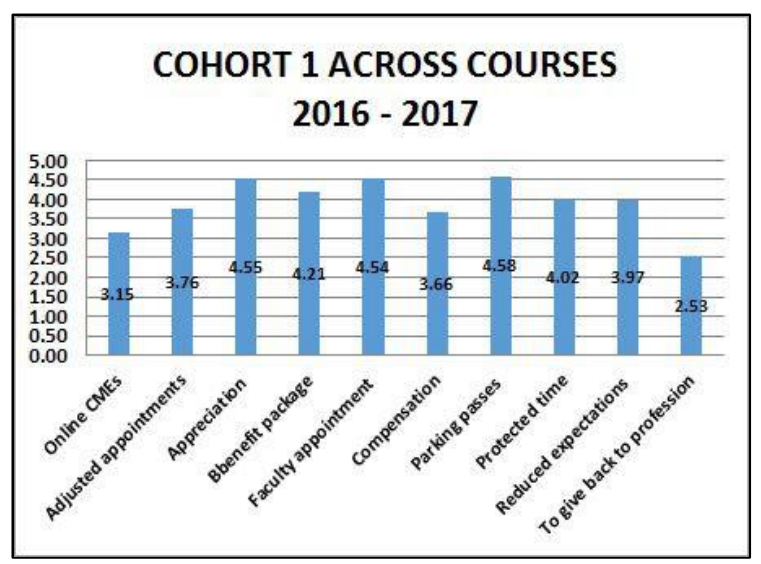

Figure 8.PM Cohort 1 across courses

Cohort 2 preceptors had a range of $2.9-4.73$, with an overall mean score 4.11. These responses were also consistent with previous baseline data, comparative data between beginning and advanced courses, and across two cohorts (see Figure 9).

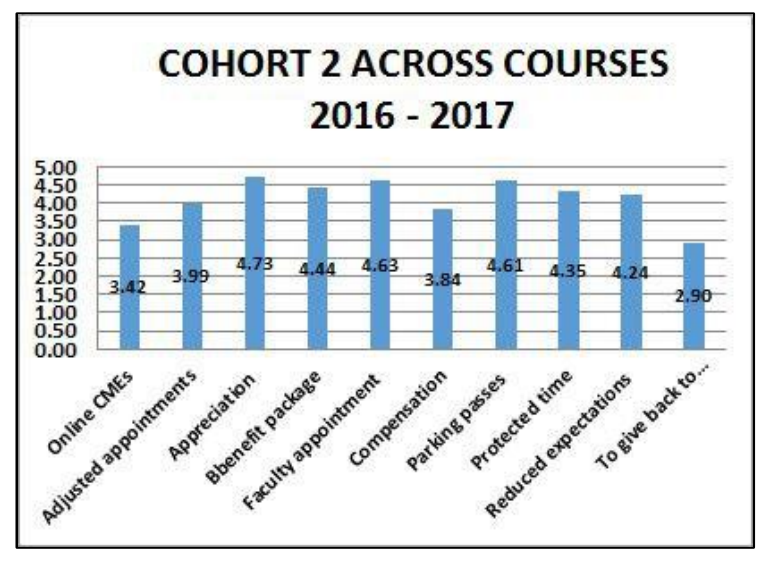

Figure 9. PB Cohort 2 across courses

A one-way between subjects ANOVA was conducted to compare the effect of cohorts on preceptor responses. There was no significant effect of cohorts on barriers of being a preceptor at $p<.05$ level for three conditions: between groups, within groups, or total $[\mathrm{F}(1,18)=4.41, \mathrm{p}=0.68]$, indicating stable responses by preceptors between Cohort 1 and Cohort 2 across courses.

A one-way between subjects ANOVA was conducted to compare the effect of cohorts on preceptor responses for motivators. There was no significant effect of cohorts on motivators for being a preceptor at $\mathrm{p}<.05$ level for three conditions. [F $(1,20)=4.35, \mathrm{p}=0.64]$, indicating stable responses by preceptors about barriers and motivators between Cohort 1 and Cohort 2 across courses.

\section{Discussion}

There appears to be only slight shifts in the top preceptor barriers and motivators to being a preceptor for DNP students. In these preceptors, in advanced and beginner courses in 2015 and 2016 and in preceptors as they progressed with students across courses in Cohort 1 and Cohort 2, giving back to the profession which is a motivator that reflects a high degree of professionalism altruism remained the most important reason these preceptors choose to teach students in the clinical arena while doing practicing their skills. A significant barrier for preceptors in both years for both courses and in both cohorts longitudinally across courses was decreased productivity. The 'type of student' was also important. Additionally, creating mechanisms to provide continuing education credits for preceptors may be helpful as a recruitment and retention strategy. This seems logical, because practice environments contain productivity and time pressures that equate to monetary reimbursement for preceptors.

One trend that draws particular attention to our faculty is that the length of clinical rotations and the number of hours a preceptor is expected to have a student has risen in rank among the barriers to being a preceptor. Between the first and second cohort, the co-preceptor model has been more fully implemented in our clinical sites. The model when fully implemented calls for an "immersive clinical experience." This reflects a fundamental increase in the number of hours any one preceptor would be expected to precept any one student as students stay within one clinical site. Previously students would rotate clinical sites with each clinical course. Further attention to mechanisms to provide continuing education credits is also warranted.

This study will continue to be administered at the end of the spring 2018 semester so strong relationships between beginning and advanced courses as well as between student cohorts across courses may be established.

Results of the ENTICE survey will continue to be collected and analyzed by cohorts and by courses. The survey is approved through the University of Arkansas IRB to be administered 
anonymously, so it will not be possible to identify individual preceptor responses to determine how their responses change or remain stable over time. However, dissemination of the group data will be beneficial to nursing programs at all levels who use preceptors to aid students to learn the role of the degree/certification which they aspire to gain.

\section{Case Report: Application of Findings}

"As a clinical and didactic professor, I had not been overly concerned about why preceptors decide to take on this onerous task without pay and frequently without recognition. I have been a preceptor, clinical instructor, and course professor for many levels of nursing students, and did most of it without compensation. I did not give it much thought... it was just something I liked to do. So, for this study, I found particular interest in digging deeper and discovering just what makes preceptors take on this challenge. In addition to my past experience, I was asked to again address incoming DNP students about how to select a preceptor. The first part was quite simple. I recommended to select a preceptor who had expertise in the area of practice each student planned to practice after graduation and national certification. However, based on my experience collecting, analyzing, and reporting the ENTICE data, I found myself responding differently this year. I recommended students ask potential preceptors what their biggest barrier and most significant motivator to be preceptors were for them.

Feedback I received from students supported findings of this longitudinal and comparative study. "I like to teach", "because someone did it for me", and "it helps me review current practice guidelines" were common themes for preceptor motivators.

The most significant barrier certainly rang true and were consistent with the results of this study. Students reported remarks such as, "I don't have enough time", "it decreases my productivity", and "I have to go slower and see fewer patients when precepting students" were reasons students reported preceptors gave them. All students reported these were preceptors who readily agreed to be their preceptor for an emersion experience across the program.

As a result of this study, I believe I have a more valid and realistic way to assist students select preceptors. I will be able to help students match their clinical experiences with consistently excellent preceptors, and I will be able to assist preceptors to agree to act as preceptor to strong, highly skilled DNP students."

\section{Conclusion}

Preceptors agree to teach, coach, and mentor DNP students because someone did it for them. They wish to 'give back' to their profession. They meet obstacles with the biggest barrier being that they lose their productivity because of the increased time needed to teach each student. Provider productivity measures need to be adjusted to accommodate for this extra time. Students and preceptors should have common course and personal goals that are compatible in order to provide the best learning experience. Academic institutions have access to online platforms to provide ongoing preceptor education with continuing education credit and to fulfill the 2016 NONPF criteria for evaluation of NP programs. The provision for preceptor orientation and education could be incorporated into the clinical site agreements between institutions and academe. However, because orientation to a program or specialty is now a criteria from which nursing programs will be evaluated, emphasis may be placed more on orientation than on continued provider education. This may in fact be a deterrent to busy, clinical preceptors.

\section{References}

[1] R. Donley, M. Flaherty, E. Sarsfield, A. Burkhard, S. O'Brien, and K.M. Anderson. "Graduate Clinical Nurse Preceptors: Implications for Improved Intra-Professional Collaboration", The Online Journal of Issues in Nursing, American Nurses Association, Silver Spring, Maryland, July 31, 2014, Volume 19, Issue 3. http:// www.nursingworld.org/MainMenuCategories/ANA Marketplace/ANAPeriodicals/OJIN/TableofContents/Vol19-2014/No3-Sept-2014/Articles-Previous-Topics/ Graduate-Clinical-Nurse-Preceptors.html. (Access Date: 12 June, 2017).

[2] K. Hyrkäs, and M. Shoemaker. "Changes in the preceptor role: re-visiting preceptors' perceptions of benefits, rewards, support and commitment to the role", Journal of Advanced Nursing, Blackwell Publishing, Oxford, United Kingdom, 2007. Volume 60, Issue 5, 118513-524. https://www.researchgate.net/publication/ 
5872074_Changes_in_the_preceptor_role_Revisiting_pre ceptors\%27_perceptions_of_benefits_rewards_support_ and_commitment_to_the_role (Access Date: 12 June 2017).

[3]B. Peyser, K. Daily, N. Judak, K. Railey, and H.Bosworth. "Enlisting new teachers in clinicalenvironments (ENTICE); novel way to engage clinicians",Advances in Medical Education and Practice, DovePublishing Ltd. Princeton, New Jersey, 4 October, 2014,Volume 5, pp. 359-367.https://www.dovepress.com/ enlisting-new-teachers-in-clinical-environments-enticenovel-ways-to-e-peer-reviewed- article-AMEP (Access Date: 12 June, 2017).

[4]Interprofessional Education Collaborative. "CoreCompetencies for interprofessional collaborative practice:2016 update", Interprofessional Education Collaborative, Washington, D.C., https://ipecollaborative. org/uploads/IPEC-2016-Updated-Core-Competencies Report final_release_.PDF. (AccessDate: 12 June, 2017).

[5]J.F. Giddens, L. Lauzon-Clabo, P.F. Morton, P.Jeffries, and S. Ryan. "Re-envisioning Clinical Educationfor Nurse Practitioner Programs: Themes from a NationalLeaders' Dialogue" Journal of Professional Nursing,2014, Number 30, Volume 3, pp. 273-78. http:// www.profes-sionalnursing.org/article/S8755-7223

(14)00060-X/abstract. (Access Date: 12 June, 2017).

[6]NONPF, AACN, and NTF on Quality NursePractitioner Education. "2016 Criteria for evaluations ofnurse practitioner programs, 5th edition.", Washington,D.C., http://www.aacnnursing.org/Portals/ 42/AcademicNursing/pdf/Criteria-Evaluation-NP-2016. pdf?ver=2017-05-17-105947-533.

Disclosure: Mutually Beneficial Clinical Partnership\# D09HP28679 \$1,081,736.00 2015 - 2018 is financed $100 \%$ by HRSA. This information or content and conclusions are those o the authors and should not be construed as the official position or policy of, nor should any endorsements be inferred by HRSA, HHS or the U.S. Government." 